\title{
Harmonisation of Penalties and Sentencing within the EU
}

\author{
PETTER ASP*
}

\section{Introduction}

This short article focuses on the harmonisation of penalties and sentencing. The text is written in an EU perspective, i.e., it is written having the development of the (criminal law part of the) Area of Freedom, Security and Justice in mind. Ultimately, it aims at justifying the conclusion, or at least at suggesting, ${ }^{1}$ that we - the EU and its Member States - should proceed carefully with harmonisation in this area and that harmonisation of sentencing should be looked upon as sort of a last-stage-harmonisation, i.e., harmonisation of sentencing is a type of harmonisation that one should not focus on before having reached a fairly high degree of harmonisation of the criminal law systems in general. In short, this means that the present focus on establishing minimum-maximum rules is perhaps - even though it is clear that the practical results of such a harmonisation is very limited - not that bad. Albeit the minimum-maximum approach leads to a situation where we spend time negotiating rules which are, to say the least, not very important in practice, the carefulness that is hiding behind the minimum-maximum thinking can perhaps be justified if looked upon in a larger perspective?

\section{$2 \quad$ Harmonisation of penalties - and sentencing?}

When discussing harmonisation of penalties and sentencing it may be a good start to try get a clear picture of what we are discussing. It seems obvious that one can approach the harmonisation of penalties and sentencing in different ways and with different levels of ambition.

For the purpose of setting the map and thereby enhancing the possibilities to discuss the harmonisation of penalties and sentencing in a more nuanced way it is therefore valuable to make some basic distinctions.

Petter Asp is Professor of Criminal law at the Faculty of Law, University of Stockholm.

I do not, e.g., even make an attempt to discuss all the relevant materials, and I do not provide full references to instruments, documents and articles of interest. 
First one can, of course, in the same way as one often does when discussing rules on criminal responsibility, make a distinction between the special part of sentencing law and the general part of sentencing law. The general part would under such a distinction consist of rules applicable in relation to all offences (or to most offences; the general part does not, of course, have to be completely general) while the special part would consist of rules applicable to single offences (as regards sentencing, the special part is often limited to setting maximas and minimas). For example, rules stating that the seriousness of the offence should be the primary factor when deciding a sentence, rules stating that courts should take prior convictions into account when sentencing, rules that clarifies that courts are allowed to go below the statutory minimum if there are special reasons to do so etc. would belong to the general part, while rules stating that theft should be punished by a minimum of one year of imprisonment and rules stating that that certain factors should be considered as aggravating when sentencing a specific offence would belong to the special part.

Another, though partly overlapping, ${ }^{2}$ way of approaching harmonisation of sentencing is to make a distinction between:

(a) applicable penalty scales, i.e., rules that set the formal frames within which sentencing decisions are made,

(b) rules on how to use the penalty scales, i.e., rules that decide how to "behave" within the frame, and

(c) a result, i.e., a concrete outcome of (a) and (b).

Such a simple division of the process of sentencing could then be used for the purpose of discussing the prospects of possible harmonisation strategies. We could (as we presently do) decide to focus on the (partial) harmonisation of the penalty scales by establishing minimum-maximum-rules, but we could also (either instead or in addition) focus on harmonising rules that do not concern the scales as such, but rather the way the scales should be used (e.g., rules clarifying the primary rationales for sentencing, rules on aggravating and mitigating circumstances, rules on how to take prior convictions into account etc.). Yet another possibility would be to simply focus on the result, i.e., to require a certain outcome (while letting the Member States decide the way of reaching the result). Such result oriented requirements can, of course, be made quite specific. For example, it could be required that a certain offence in the end results in a quite specific sentence, e.g., that fraud involving 10000 Euro should lead to imprisonment of (at least) 6 months. However, result oriented requirements could also be held (very) general. They could, for

\footnotetext{
Generally speaking (a) will be equal to the special part (since penalty scales are normally attached to specific offences) and (b) to the general part (since rules on how to make use of the penalty scales are normally generally applicable). However, there is nothing that excludes the combination (a)/general part (i.e., general rules which merely sets the frame for sentencing) or (b)/special part (i.e., rules on how to use a specific penalty scale).
} 
example, state that the Member States should make sure that the sentences produced for a certain offence type are deterrent (or that they fulfil the well-known "effective, proportionate and dissuasive"-requirement). ${ }^{3}$

A third and once again partly overlapping, distinction that could be used is a more general distinction between:

(a) a focus on reasons or on thinking on the one hand, and

(b) a focus on results on the other.

Thus, a focus on results could be contrasted with a focus on "thinking" or on "structures and rationales" where the interest is not primarily in achieving unity in outcome (at least not immediately) but rather to streamline and unify the thinking. Such harmonisation of thinking, though, could of course be done for the purpose of facilitating future harmonisation. It is, arguably, easier to harmonise rules at surface level if the underlying ideas are, at least to some extent, the same. It is, for example, probably easier to harmonise the concept of offence seriousness if the states involved have a common basic understanding of the ways in which offence seriousness is important in the sentencing process. In short and put more generally: it will in the end be easier to agree upon details and upon "surface level" regulations if there is a shared understanding of the purpose and principles of the sentencing process as such.

There are, of course, other distinctions that can be made and other ways in which one can discuss harmonisation of penalties and sanctions, but I will stop here and with this said as a starting point say a few words about the way things are done today (section 3) and about the general prospects of the future harmonisation of sentencing (section 4).

\section{The way things are done today}

Until now, harmonisation of sentencing has first and foremost meant that the EU has decided upon minimum-maximum penalties for different types of offences, i.e., the EU has adopted instruments requiring that the Member States must have a maximum penalty, which is at least on a certain level, attached to the offence upon which the instrument in question focuses. As one example we could refer to Article 3(6) of the Directive on combating the sexual abuse and sexual exploitation of children and child pornography:

\footnotetext{
6. Coercing, forcing or threatening a child into sexual activities with a third party shall be punishable by a maximum term of imprisonment of at least 10 years if the child has not reached the age of sexual consent, and of at least 5 years of imprisonment if the child is over that age.
}

Reasonably, this would require that the result is within the available scale (thus harmonisation focusing on results would, to a certain extent, require harmonisation of scales). 
Thus, if we use the framework sketched in section 2 for the purpose of analysing how things are done today one could say:

(1) that the harmonisation of penalties and sentencing has been limited to the special part (it has been limited to specific offences),

(2) that it has primarily ${ }^{4}$ been limited to the first step in the sentencing process, and

(3) that there has been a focus on result rather than on thinking.

This focus on specific levels attached to specific offences is quite natural having regard to the competences of the EU under the Treaty on the Functioning of the European Union (TFEU). According to Article 83 TFEU, the EU has the competence to 'establish minimum rules concerning the definition of offences and sanctions', but the competence relates directly to the offences under article 83(1) and 83(2) TFEU. Thus, it is quite clear that the competences of the $\mathrm{EU}$ in the area of sentencing are limited.

First, it is limited in the sense that the competence to harmonise penalties forms an annex to the competence to establish minimum rules concerning the definition of certain offences-either (i) it forms an annex to those particularly serious cross border offences mentioned in Article 83(1) TFEU or (ii) an annex to the annex-offences as defined in Article 83(2) TFEU. Thus, there is no general competence as regards sentencing which is independent of the competence relating to the offence categories covered by Article 83 TFEU. Arguably, this means that the EU lacks the competence to issue rules with general application, e.g., rules stating that when sentencing (in general), the judge should have regard to factors $\mathrm{x}, \mathrm{y}, \mathrm{z}$. Another way of expressing this is to say that the competences conferred upon the EU in this regard are presently limited to the special part of sentencing law.

Second, the competence of the EU is limited to the establishment of 'minimum rules'. Although the wording of the TFEU to some extent leaves it open what exactly the minimum should relate to-minimum rules relating to the type of sanctions used (the punishment should involve more than mere fines, the punishment should as a minimum include deprivation of liberty etc.), minimum rules relating to the maxima and/or minima attached to the offence in the offence description (the maximum and/or the minimum penalty should at least be at a certain level), minimum rules relating to the concrete sentencing decisions in individual cases (the courts must impose an actual sentence of at least $\mathrm{x}$ months) etc. - it is clear that the limitation to minimum rules will mean that focus will primarily be on rules or areas where it is possible to formulate fairly concrete borders. As regards harmonisation of sanctions this has, so far, meant a focus on numbers, and it seems likely that the minimum rules-approach will continue to direct us towards numbers, i.e., that focus will continue to be on minimum levels expressed in numbers,

There are exceptions though. See, e.g., the rules on aggravating and circumstances in Article 9 of Directive 2011/92/EU on combating the sexual abuse and sexual exploitation of children and child pornography. 
either on an abstract level (minimum levels as expressed in the law), or on a concrete level (minimum levels in concrete sentencing decisions). This is not to say, however, that other types of harmonisation of sentencing related rules attached to specific offences are not conceivable. ${ }^{5}$

Hence, to make it possible to harmonise sentencing in a broader meaning-including the general part of sentencing law - the treaties will probably have to be amended. From this it follows that more far reaching harmonisation of sentencing is, for purely competence related reasons, mainly a question for the future.

In this context, it could be noted that the possibility to establish general rules on sanctions was, probably, bigger before the entry into force of the Lisbon Treaty than afterwards, i.e., under the former third pillar the borders to the competences were less clear than they are now, and the possibilities for the Member States to decide (unanimously) what the competences contained were arguably greater. ${ }^{6}$

Though the competences of the EU to harmonise the general part of sentencing law must be considered to be limited or non-existent there is, of course, nothing that prevents EU law in general from affecting sentencing practices in the Member States. First, there is a general EU law obligation on part of the Member States to protect EU interests in a similar way as they protect their corresponding national interests (the principle of assimilation) and, as a minimum, by making use of sanctions that are effective, proportionate and dissuasive. ${ }^{7}$ If taken seriously these requirements set up at least some sort of outer limits for the sentencing practices in the Member States; these limits should primarily be taken into account at the legislative level in the Member States, but if necessary and if possible, also by national judges when deciding concrete cases.

Second, there is the general proportionality requirement in Article 49(3) of the Charter of Fundamental Rights of the European Union:

3. The severity of penalties must not be disproportionate to the criminal offence.

If this reference to proportionality was understood as requiring proportionality to be the primary sentencing rationale, the article would indeed imply quite far reaching harmonisation of the basic rationales for sentencing within the EU. It seems clear, however, that the article cannot reasonably be interpreted in that way. ${ }^{8}$ Arguably, Article 49(3) of the Charter rather aims at excluding clearly disproportionate sentencing, i.e., at excluding punishment which does not stand in any reasonable relation to the offence in question.

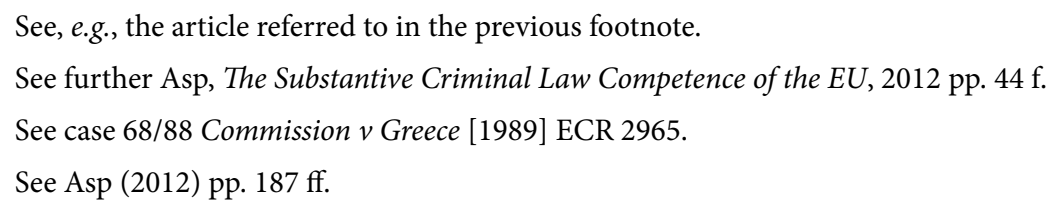


All in all, it seems fair to say that both the minimum requirements that follow from the case law of the Court of Justice and the proportionality requirement that follows from the Charter of Fundamental Rights are so general that they do not provide for any real harmonisation. Rather they provide some outer limits which must be respected (ruling out only penalties which are clearly not dissuasive, which are clearly disproportionate to the offence in question etc.).

\section{$4 \quad$ Reasons to be careful}

As displayed above, it is highly questionable whether the EU has the competence to harmonise sentencing law in general. Even if the EU had such competence there would however be reasons for restraint, i.e,. reasons to be careful and to have limited and realistic ambitions in this area. In this section I will tentatively list the most important reasons for such restraint.

First of all, sentencing is arguably an area where arguments based on the national identity and the traditions of the Member States (see Articles 4(2) Treaty on European Union and 67(1) TFEU) are especially important. It is also an area where the principle of coherence is of special importance.

(a) Sentencing reflects values held by the community very directly and it does not only-as the criminal law system in general-reflect the division between what is acceptable and what is not, but also the way different values relate to each other and how one reaches a compromise between different interests. Further, sentencing is an area which brings to the fore our understanding of judicial discretion, i.e., it brings to the fore how we look upon the relation between the legislature and the judges. In some Member States the responsibility and discretion of judges when it comes to questions of sentencing is considered to be something which constitutes an essential part of the very idea of being a judge and which ultimately concerns (or is thought of as concerning) the independence of the judiciary. In other states sentencing is more or less considered to be one legal area among others within which it is quite natural to try to direct the judges by means of legislation. Thus, sentencing is an area which brings to the fore very basic understandings of the legal system and its actors. ${ }^{9}$

(b) Sentencing is an area where we should not expect a common understanding even as regards the basic principles or the rationales. There is, of course, reason to believe

See, similarly, Nuotio, "Harmonization of Criminal Sanctions in the European Union - Criminal Law Science Fiction" in Harmonization of Criminal Law in Europe (eds. Husabo and Strandbakken) 2005 p. 98 : "To exaggerate just a little: we have very different views on what the legal character of sentencing is about: in France or Italy the judge exercises a wide discretion regarded as free, whereas in the North the principles guiding this discretion are regarded as legally binding, and the courts have a duty to give reasons for their decisions. Such legal theoretical understandings, of course, may have a great impact on how such decision-making can be guided and influenced, if necessary." 
that rationales such as desert (proportionate punishment), general prevention and special prevention play some role in all or most sentencing systems that exist within the EU, but the ways in which these rationales come into play vary manifestly between different Member States. If one looks at Germany and Sweden as examples one will, e.g., find many similarities as regards the rules on construction of criminal responsibility (i.e., there are many similarities between the 'Straftatlehren' in the two states), but one will find quite substantial differences when it comes to sentencing and the thinking about sentencing. For example, the 'Spielraumtheorie' which is central in German theory is more or less explicitly rejected in Sweden where the idea of relative proportionality as being more than merely limiting is quite strong. ${ }^{10}$

(c) Sentencing is, despite the differences just described, an area of law where the interest in relative proportionality is very strong in most Member States. Though there are substantive differences between the sentencing systems of the Member States as regards the structure and thinking, most (or all) criminal law systems do, in one way or the other, rank offences in relation to each other, and albeit there are huge differences between the systems as regards the way this ranking is made (both as regards the way offences are being ranked in relation to each other and as regards the general level of repression) this means that the laws of the Member States form some sort of normative systems. And as all normative systems they are sensitive to foreign elements, which disturb the internal order of the respective system. This can be illustrated as follows:

"If we assume, as there is good reason to do, that:

(1) the Member States strive for coherence within their own systems, i.e., they try to rank their offences in a coherent way, and

(2) there are differences between the Member States as regards both the way they rank different offences and the general level of repression,

then this means in practice that each and every directive will by necessity disturb the inner coherence of at least some of the criminal law systems existing in the Union. The differences existing between the Member States simply make it impossible for the sanctions provided for in a directive to fit in all of the criminal law systems of the Member States.

Let us take an example. Assume that the normal penalty for smuggling of migrants varies considerably between the Member States. In some states the punishment for a standard case of this offence might be 1 year; for example in state $\mathrm{A}$; in others, for example state $\mathrm{B}$, the punishment in a standard case is 2 years, and in yet others, state $\mathrm{C}$, it might be 4 years. This means that no matter whether the EU decides on a level of sanctions of 1, 2, 4 or 6 years, the instrument taken will disturb the inner coherence of either state A, B or C." ${ }^{11}$

10 See, e.g., von Hirsch, Past and future crimes, 1985 pp. $38 \mathrm{ff}$.

$11 \quad$ Asp (2012) p. 210. See also Nuotio, “The Emerging European Dimension of Criminal Law." in Flores juris et legum. Festskrift till Nils Jareborg (eds. P. Asp, C.E. Herlitz and L. Holmqvist), 2002, pp. 557 f. 
This is not necessarily a reason for not doing anything in this area but it is a reason for not trying to do too much too fast. ${ }^{12}$

(d) Sentencing rules cannot be fully separated from rules on criminal responsibility. Rather, it should be acknowledged that the rules on sentencing often reflect positions taken on substantive criminal law issues. Though one can, to some extent, separate questions relating to responsibility from questions relating to sentencing-for example, one can put great emphasis on general preventive considerations in sentencing without giving such considerations any weight when deciding upon questions of responsibility-it seems impossible to make to make a full separation between the two types of questions without getting into serious axiological problems, i.e., one cannot, if one wants to have a reasonably coherent system, decide on the rules of sentencing without having any regard to the way the rules on criminal responsibility are constructed. The construction of the rules on responsibility will, for example, have to reflect-to some extent at least-on sentencing, should it be possible to avoid drastic thresholds within the system. Let us assume, for example, that a person is acting in self-defence and is almost, but not fully, justified. In such a situation the fact that the person was acting in a self-defence situation must, arguably and reasonably, be taken into account at the sentencing stage. Similarly, if a certain criminal law system makes a distinct difference between intent and negligence when criminalising-criminalising intentional conduct much more extensively due to the idea that intentional offending is more serious-then this distinction must arguably be reflected, to at least some extent, at the sentencing stage. Thus, harmonisation of sentencing is not something that could be separated from harmonisation in general; more ambitious harmonisation of sentencing presupposes (or should presuppose) harmonisation of the rules on responsibility.

Second, it should be clear that even with the greatest of ambitions it will be extremely hard to achieve unity in practice. This is due to several, but interrelated, reasons:

(a) Sentencing is not focused on the drawing of borders but about the use of a scale. Using a scale uniformly is difficult. For a university teacher an apparent analogy is the task of grading essays. To achieve uniformity is difficult already in a situation when a limited number of people within the same faculty grade essays which focus on the same topic and which are (due to instructions given to the students) quite similar in form and structure. The task is, of course, much more difficult when the grading is done by a large number of courts within a Member State and it becomes virtually impossible if we aim at uniformity at EU level, where the grading is done by courts with different traditions, different understandings of their own role etc. The difficulties become even more apparent

12 If the aim is ultimately to amalgamate the systems into one single criminal law system (this is a condition that should be taken seriously), then it will, of course, at some point be necessary to harmonise the general level of repression, the way offences are ranked in relation to each other etc. However, it seems clear that we are quite far from that point in time: today we are rather in a situation where EU criminal law is built on different criminal law systems of the Member States (which are to some extent harmonised by the EU). 
if we add that sentencing is not about grading fairly uniform units (as essays), but rather concern different types of combinations of offences committed by people of different age in different predicaments etc.

(b) Sentencing is an area where you cannot avoid discretion. Although there are differences between the Member States as regards the amount of discretion given to judges, it is clear that sentencing will remain an area where the discretion conferred upon judges will be quite substantial.

(c) Sentencing is an area where the outcome depends not only on the actual sentencing decision (or on rules on sentencing).

- the actual outcome of a sentence will also depend upon the rules on execution of sentences; one obvious example is that rules on conditional release will affect the time actually spent in prison. ${ }^{13}$

- the actual meaning of a prison sentence, i.e., what it actually means to serve a certain amount of time, will further be dependent upon the prison conditions of the Member States and it is quite obvious that they vary manifestly between the Member States.

- the symbolic meaning of a certain sentencing decision will be dependent on the legal context in which the decision is produced. A one year sentence will, just for the purpose of giving one example, communicate one thing in Finland, another thing in England and a third thing in Romania.

All in all, this means that also quite far-reaching measures aiming at the harmonisation of sentencing will probably be insufficient if we are striving for unity in practice.

Third, there is arguably not much to be won by harmonising sentencing (at least not at as an early-stage-measure).

(a) It is, in general, very hard to know with certainty how the design of the criminal law system affects crime and criminality, but having regard to modern criminology a modest and reasonable proposition is that differences in sentencing has merely marginal impact on overall crime rates. Other factors, such as the existence of an opportunity, the risk of being apprehended and the possibility to gain something, are arguably more important in this respect.

(b) It could be argued that international cooperation (including cooperation built on the principle of mutual recognition) is at times dependent upon the penalties attached to a certain offence and that harmonisation of penalties therefore facilitates cooperation. However, such an argument turns the logic of the system upside down. The very idea of making cooperation dependent upon the penalties attached to a certain offence is, of course, that the penalties say something about the seriousness of the offence in question.

The possibilities to make a prison sentence conditional (and the question whether such a sentence is still considered to be a custodial sentence) are, of course, also very important in this context. 
This idea is corrupted if one lets the need for cooperation affect the penalties attached to different offences.

All in all, I would say that the (admittedly sketchy) picture provided in this article shows that one should not be too ambitious in this area of law, at least not if looking at things in a short-term perspective. This is not to say that it is unreasonable to feel some frustration when looking at the present focus on minimum-maximum rules. Of course it is. It is quite clear that that this type of harmonisation, and this way of doing things, does not mean much of harmonisation in practice (the maximum penalty for a certain offence is seldom exerting a lot of influence on the way sentencing is conducted, and a common maximum penalty does not, of course, exclude major differences in other respects). One possible response to such frustration is, of course, to say that we need to do more than just set up some maximum-minimum penalties. Another possible response is to say that it is true that the focus on maximum-minimum levels does not really mean that much in practice, but at the present stage of the harmonisation process we should perhaps not aim for more. The very purpose of this article has been to suggest that this second response is perhaps quite reasonable. 